\title{
Content of significant amounts of a cytotoxic end-product of lipid peroxidation in human semen
}

\author{
M. L. Selley ${ }^{1 *}$, M. J. Lacey ${ }^{2}$, M. R. Bartlett ${ }^{1}$, C. M. Copeland ${ }^{3}$ and \\ N. G. Ardlie ${ }^{1}$
}

'The Australian National University, John Curtin School of Medical Research, Division of Clinical Sciences, 4th Floor, Central Health Laboratory Building, Royal Canberra Hospital South,Garran, ACT 2605, Australia; ${ }^{2}$ CSIRO Division of Entomology, Clunies Ross Street, Canberra, ACT 2601, Australia; and ${ }^{3}$ Concept Fertility Pty Ltd, King Edward Memorial Hospital, Subiaco, WA 6008, Australia

\begin{abstract}
Summary. (E)-4-Hydroxy-2-nonenal (HNE), a cytotoxic end-product of lipid peroxidation, is present in significant amounts in human semen $(0.902 \pm 0.190 \mu \mathrm{M}$; mean \pm s.e.; $n=18$ ). The addition of the divalent cation ionophore A23187 to suspensions of human spermatozoa resulted in increased production of HNE. Exogenous HNE was powerfully spermicidal and as little as $50 \mu \mathrm{m}$ caused an irreversible loss of motility of human spermatozoa within minutes. The addition of human seminal plasma protected spermatozoa from the toxic effects of HNE.
\end{abstract}

Keywords: (E)-4-Hydroxy-2-nonenal; lipid peroxidation; cytotoxicity; human seminal plasma

\section{Introduction}

(E)-4-Hydroxy-2-nonenal (HNE) (Fig. 1) was first identified as a product of the lipid peroxidation of hepatic microsomal lipids (Benedetti et al., 1980). HNE occurs normally in a number of different tissues and body fluids including plasma, liver, hepatocytes, heart, adrenal gland and testis in rats (Poli et al., 1985; Yoshino et al., 1986; van Kuijk et al., 1986), erythrocytes in mice (Buffinton et al., 1988), neutrophils, brain, retina, retinal pigment epithelium and kidney in dogs (Slakotos et al., 1988) and platelets and monocytes in man (Selley et al., 1989). Increased concentrations of HNE have been reported in the plasma and liver in rats deficient in vitamin $\mathrm{E}$ (Yoshino et al., 1986), in neutrophils, brain and retinal pigment epithelium in neuronal-retinal ceroidosis in dogs (Slakotos 't al., 1988) and in erythrocytes in malaria-infected mice (Buffinton et al., 1988).

$\mathrm{HNE}$ is a highly electrophilic agent which readily reacts with biomolecules containing sulphydryl (SH) groups including cysteine (Esterbauer et al., 1976), glutathione (Esterbauer et al., 1975) and SH proteins such as DNA polymerase (Hauptlorenz et al., 1985). HNE also reacts with amino groups in low-density lipoproteins (LDL) (Hoff et al., 1989) and deoxyguanosine (Winter et al., 1986).

HNE elicits a variety of biological effects including inactivation of glucose-6-phosphatase and cytochrome P-450 (Benedetti et al., 1980) and adenylate cyclase and 5'-nucleotidase (Paradisi et al., 1985), lysis of erythrocytes (Benedetti et al., 1980), the reduction of superoxide anion production by human neutrophils (Witz et al., 1985), potentiation of human platelet aggregation (Selley et al., 1988) and chemotaxis of rat neutrophils (Curzio et al., 1986). HNE is cytotoxic against Ehrlich tumour ascites cells (Hauptlorenz et al., 1985) and human umbilical cord vein endothelial cells (Kaneko et al., 1988); genotoxic and cytotoxic in rat hepatocytes (Griffin \& Segall, 1986); and toxic to the human malaria parasite (Clark et al., 1987). HNE inhibits the proliferative response to

*Author for correspondence. 


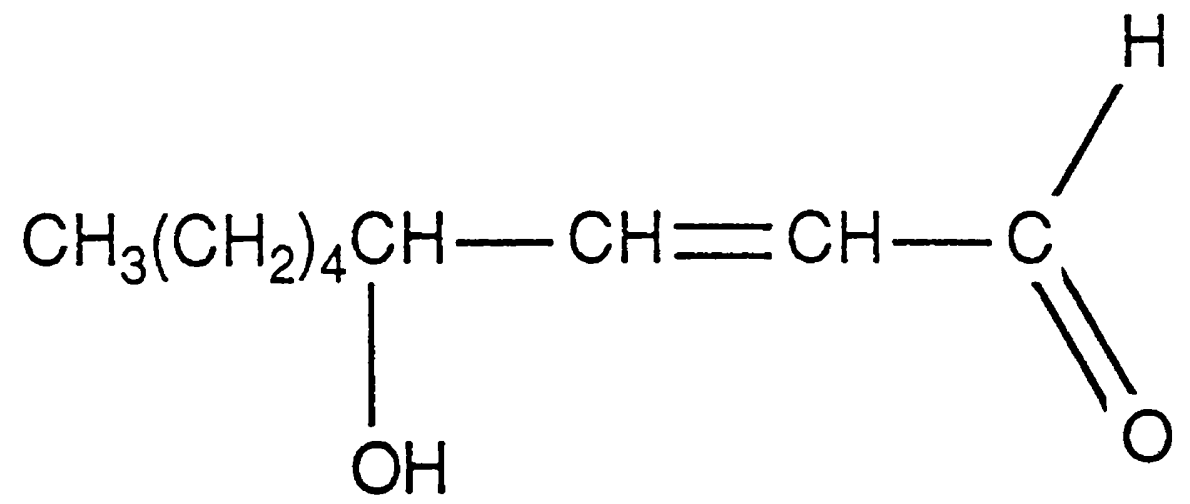

Fig. 1. Structure of (E)-4-hydroxy-2-nonenal.

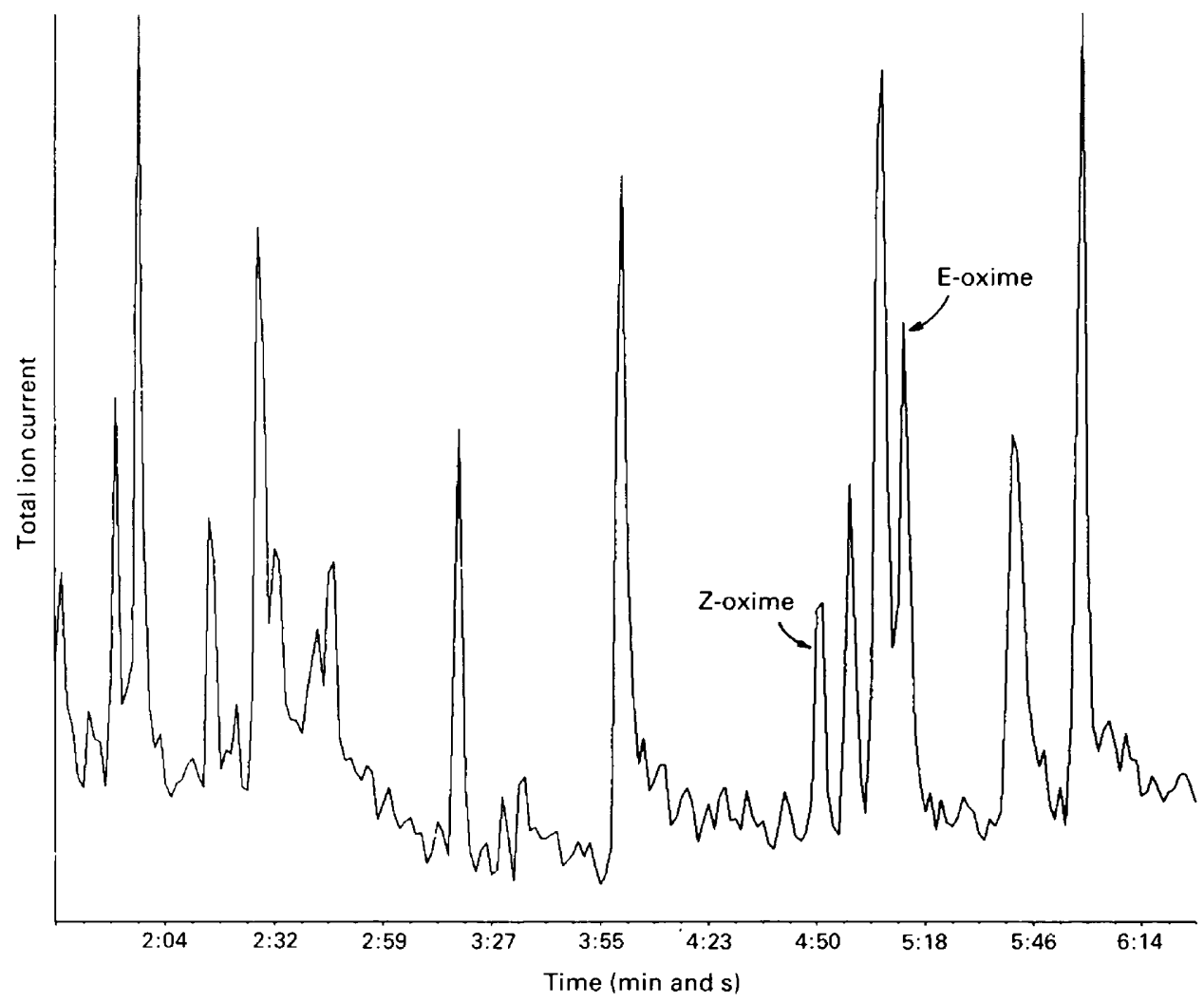

Fig. 2. Total ion current profile (capillary column gas chromatography/negative ion chemical ionization mass spectrometry) for $(E)$-4-hydroxy-2-nonenal $O$-pentafluorobenzyl oxime extracted from human semen and derivatized as its trimethylsilyl ether.

phytohaemagglutinin and alloantigens (Tessitore et al., 1987) and c-myc oncogene expression (Barrera et al., 1987) and modifies LDL, inducing enhanced uptake by macrophages (Hoff et al., 1989).

HNE is formed from arachidonic acid derived from polar phospholipids during lipid peroxidation (Esterbauer et al., 1986). Arachidonic acid is also the major source of the malonaldehyde 
produced during lipid peroxidation (Niehaus \& Samuelsson, 1968). The peroxidation of the phospholipids of human spermatozoa has been determined by measuring the malonaldehyde produced by its reaction with 2-thiobarbituric acid (TBA) (Jones et al., 1979). HNE is a highly lipophilic compound (Benedetti et al., 1980), which may lead to its accumulation in biomembranes, resulting in much higher concentrations than in free solution (Esterbauer et al., 1982). Malonaldehyde is a hydrophilic compound which does not remain in the cell membrane but diffuses into the surrounding aqueous phase (Esterbauer et al., 1982). HNE is also much more reactive than malonaldehyde (Esterbauer et al., 1982).

There is evidence that human spermatozoa are capable of producing reactive oxygen species (Aitken \& Clarkson, 1987). Since unsaturated fatty acids in the phospholipids of human spermatozoa are highly susceptible to peroxidation (Jones et al., 1979), we postulated that human spermatozoa may produce HNE. In this study, we demonstrated that human semen contains significant amounts of HNE.

\section{Materials and Methods}

The donors were healthy individuals who had been screened for antibodies against hepatitis B and HIV. All donors possessed semen profiles with $>50 \times 10^{6}$ spermatozoa $/ \mathrm{ml} ;>50 \%$ motility and $>80 \%$ normal morphology. Semen samples were collected by masturbation after 3 days of sexual abstinence and allowed to liquefy for $30 \mathrm{~min}$ at $37^{\circ} \mathrm{C}$.

Identification of HNE in human semen. HNE was identified in human semen by capillary column gas chromatography/ negative ion chemical ionization mass spectrometry (GC/NICIMS) (Selley et al., 1989). The extract was prepared immediately after liquefaction by mixing $1 \mathrm{ml}$ of semen with $20 \mu \mathrm{l}$ of butylated hydroxytoluene in methanol $(10 \mathrm{mg} / \mathrm{ml})$ and $4 \mathrm{ml}$ of $1 \cdot 5 \mathrm{M}$ sodium acetate buffer, $\mathrm{pH} 5 \cdot 0$, containing $10 \mathrm{mg}$ of $O-(2,3,4,5,6$ pentafluorobenzyl $)$ hydroxylamine hydrochloride $/ \mathrm{ml}$ on a vortex mixer for $1 \mathrm{~min}$. The mixture was cooled in ice and sonicated for $30 \mathrm{~s}$. The HNE $O$-pentafluorobenzyl $(O$-PFB) oxime derivative was extracted twice with $3 \mathrm{ml}$ of ethyl acetate and the combined extracts were evaporated to dryness under a stream of nitrogen. The residue was extracted in $3 \mathrm{ml}$ of distilled water and purified on a $\mathrm{C}_{18}$ reversed-phase cartridge. The $\mathrm{HNE} O$-PFB oxime derivative was isolated by highperformance liquid chromatography and derivatized further to the trimethylsilyl (TMS) ether derivative as described previously (Selley et al., 1989).

Quantification of HNE in semen. The determination of HNE in individual ejaculates was achieved by GC/NICIMS using selected ion monitoring with deuterated HNE as the internal standard (Selley et al., 1989).

Production of HNE by spermatozoa. Spermatozoa from separate semen samples obtained from different donors were isolated by centrifugation at $550 \times \boldsymbol{g}$ for $5 \mathrm{~min}$. The seminal plasma was aspirated and $0.5 \mathrm{ml}$ of modified Whittingham's T6 medium without foetal bovine serum (Trounson, 1983) layered over the pellet. The spermatozoa were incubated for $30 \mathrm{~min}$ at $37^{\circ} \mathrm{C}$ and the upper part $(0.3 \mathrm{ml})$ was aspirated. The concentration of spermatozoa in the aspirate was determined with a haemocytometer and the spermatozoa were resuspended at a concentration of $16 \times 10^{6} / \mathrm{ml}$. To a $500 \mu \mathrm{l}$ aliquot of spermatozoa was added $5 \mu \mathrm{l}$ of a solution of A23187 in dimethylsulphoxide (DMSO) ( $10 \mathrm{~mm}$ ). DMSO alone was used in control experiments. After $5 \mathrm{~min}$, a $200 \mu \mathrm{l}$ aliquot of the suspension was removed and the HNE content determined (Selley et al., 1989).

Effect of exogenous HNE on spermatozoa. Spermatozoa were isolated by the swim-up procedure, and resuspended in modified Whittingham's T6 medium without foetal bovine serum at a concentration of $5 \times 10^{6} / \mathrm{ml}$. In some experiments, seminal plasma prepared by centrifugation of fresh ejaculates was added to give a concentration of $25 \%(\mathrm{v} / \mathrm{v})$. HNE prepared by synthesis (Esterbauer \& Weger, 1967) was dissolved in distilled water and the exact concentration determined spectrophotometrically as previously described (Selley et al., 1989). This solution $(10 \mu \mathrm{l})$ was added to the suspension of spermatozoa $(300 \mu \mathrm{l})$ to give the desired final concentration of HNE. The spermatozoa were then incubated at $37^{\circ} \mathrm{C}$ and the number of motile sperm in relation to the total number was determined at intervals using phase-contrast microscopy.

Statistical analysis. Statistical analysis was performed using Student's $t$ test for paired observations. Differences were considered to be statistically significant when $P<0.05$.

\section{Results}

\section{Identification of HNE in human seminal fluid}

The $O$-PFB oxime TMS ether derivative of HNE was distinguished in the total ion current profile as a pair of peaks of characteristic relative proportion and retention time (Fig. 2). The NICI 
(a)
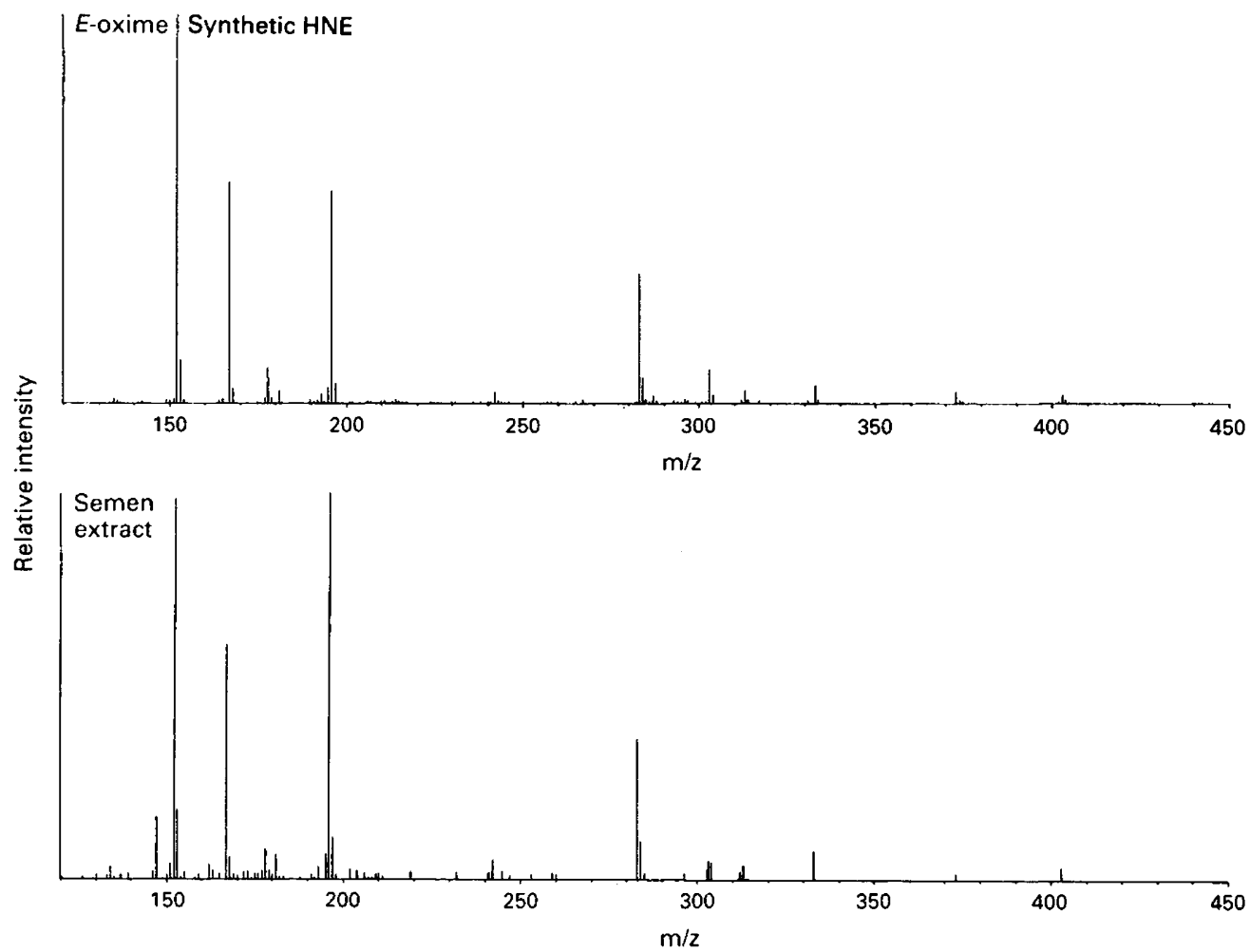

(b)

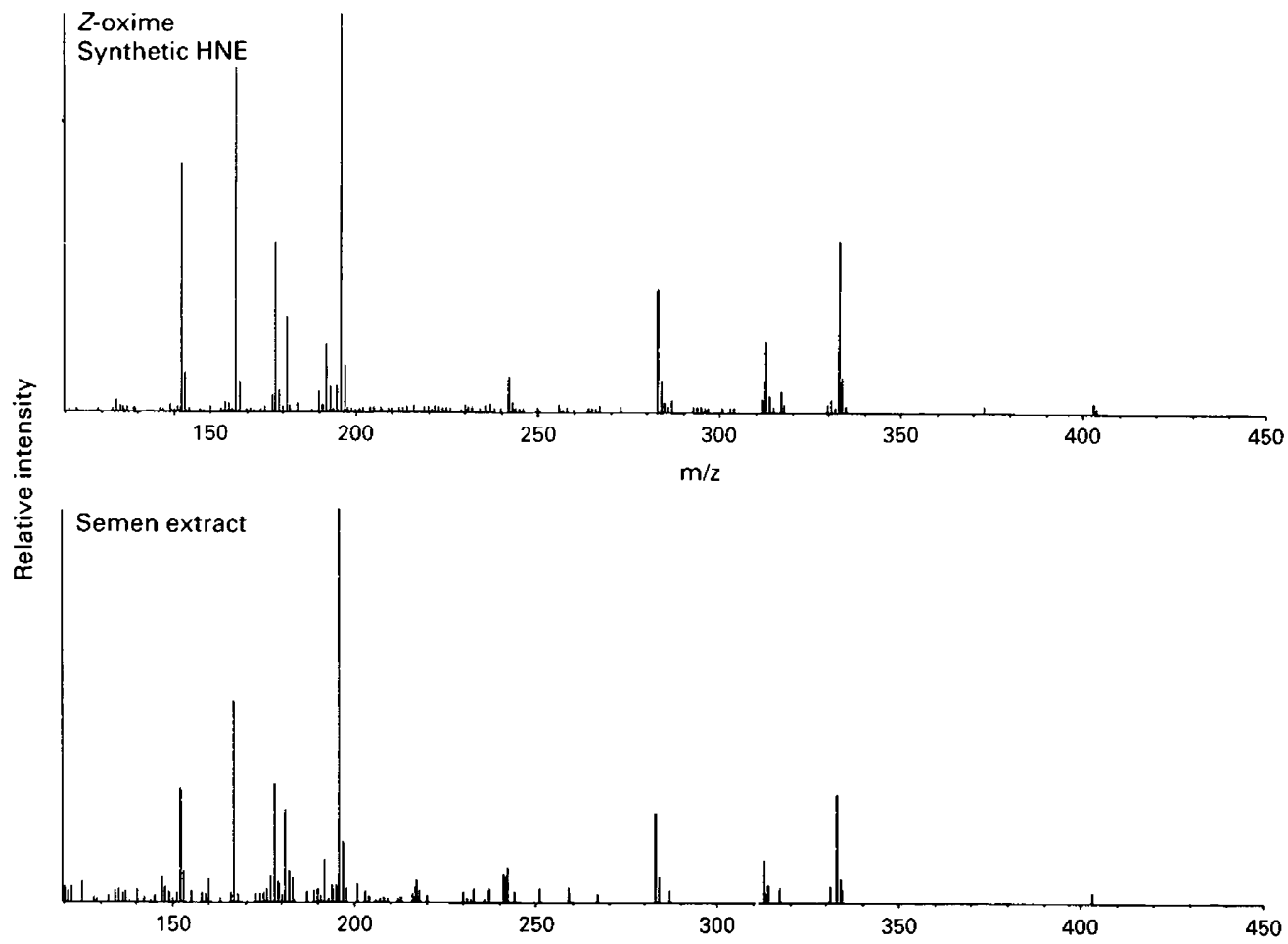


mass spectra of these isomeric components were consistent with those of the $E$ - and $Z$-isomers from synthetic HNE $O$-PFB oxime TMS ether (Fig. 3). The concentration of HNE in individual ejaculates was $0.902 \pm 0 \cdot 190 \mu \mathrm{M}$ (mean \pm s.e., $n=18$ ), range $0 \cdot 120-2 \cdot 688 \mu \mathrm{M}$.

\section{Production of HNE by spermatozoa in response to A23187}

Human spermatozoa produced HNE at a mean concentration of $0.013 \pm 0.004 \mu \mathrm{M}(\mathrm{mean} \pm$ s.e.; $n=12$ ). The mean concentration of HNE following the addition of the divalent cation ionophore A23187 in the presence of calcium was $0.018 \pm 0.005 \mu \mathrm{M}$ (mean \pm s.e.; $n=12$ ). The increase in $\mathrm{HNE}$ production in the presence of A23187 was statistically significant $(P<0.05)$.

\section{Spermicidal effect of HNE}

When a suspension of human spermatozoa isolated by swim-up was treated with exogenous HNE at $50-250 \mu \mathrm{M}$, a proportion of the spermatozoa became totally and irreversibly immobile within minutes (Fig. 4). The addition of seminal plasma had a protective effect, increasing the survival time of spermatozoa (Fig. 4).

\section{Discussion}

In this study, we identified HNE as a constituent of normal human semen using GC/NICIMS. There was a considerable variation in the concentration of HNE in individual ejaculates. The concentrations of HNE in human semen were approximately 1000 times higher than those observed in rat plasma (Yoshino et al., 1986) and were about half those produced after the stimulation of lipid peroxidation by carbon tetrachloride or ADP-iron in isolated rat hepatocytes (Poli et al., 1985).

The production of HNE by human spermatozoa isolated by the swim-up procedure indicates that spermatozoa are probably at least partly responsible for the HNE found in semen. It has been demonstrated previously that the major reactive oxygen species produced by human spermatozoa in response to $\mathrm{A} 23187$ in the presence of calcium is the superoxide anion radical (Aitken \& Clarkson, 1987). The superoxide anion itself is not particularly reactive but it can generate the hydroxyl radical in the presence of transition metal ions which could then stimulate lipid peroxidation (Slater, 1984). Since unsaturated fatty acids present in the phospholipids of human spermatozoa are highly susceptible to peroxidation (Jones et al., 1979), oxygen-free radicals generated by spermatozoa may be involved in the production of $\mathrm{HNE}$.

Since foetal calf serum reacts with HNE, the spermicidal effects of HNE were studied in serumfree medium (Kaneko et al., 1988). Exogenously added HNE was spermicidal to spermatozoa at concentrations similar to those at which it is cytotoxic in vitro to a number of other cell types (Hauptlorenz et al., 1985; Griffin \& Segall 1986; Tessitore et al., 1987; Kaneko et al., 1988). HNE is highly lipophilic (Benedetti et al., 1980) and, if it is formed from the polyunsaturated fatty acids of spermatozoa, it could accumulate in spermatozoa and reach concentrations much higher than those in seminal plasma.

Fig. 3. (opposite) Comparative mass spectra (capillary column gas chromatography/negative ion chemical ionization mass spectrometry) for synthetic and endogenous samples of (a) the $E$ - and (b) Z-oxime isomers of $(E$ )-4-hydroxy-2-nonenal (HNE) $O$-pentafluorobenzyl oxime trimethylsilyl ether $\left(M_{\mathrm{r}} 423\right)$. Spectra were obtained from a VG Micromass $70-70$ mass spectrometer interfaced to a Hewlett-Packard 5792A capillary gas chromatograph, using ammonia as the negative ion chemical ionization reagent gas. 

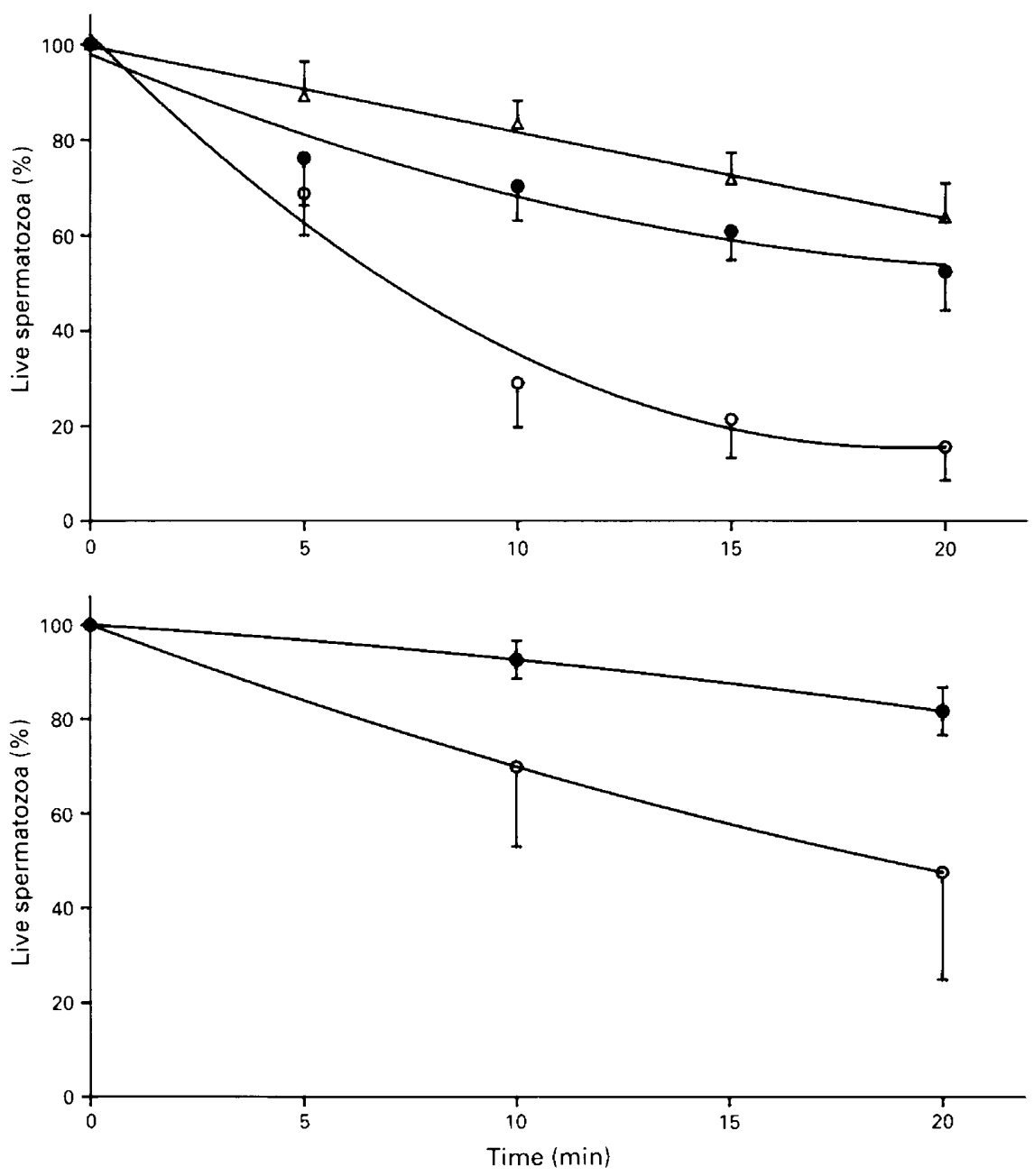

Fig. 4. Spermicidal effect of exogenous $(E)$-4-hydroxy-2-nonenal (HNE) and the protective effect of seminal plasma on the motility of human spermatozoa. Each value represents the mean \pm s.e. of at least five experiments; (a) $50(\triangle), 100(\bigcirc)$ and $250(\bigcirc) \mu \mathrm{M} \mathrm{HNE}$; (b) $125 \mu \mathrm{M}$ $\mathrm{HNE}+$ plasma (O), $125 \mu \mathrm{M} \mathrm{HNE}(\mathrm{O})$.

It has been shown that the production of reactive oxygen species by human spermatozoa is inversely related to their ability to exhibit sperm-oocyte fusion (Aitken \& Clarkson, 1987). The considerable variation in the concentration of HNE in seminal fluid together with its effects on the motility and survival of spermatozoa suggest that the excessive generation of HNE might be associated with male infertility.

It has been demonstrated that in sea urchins increases in the reactivity of SH groups occur upon the activation of sperm (Hino et al., 1986). There is a correlation between increases in intracellular $\mathrm{pH}$ during sperm activation and increased $\mathrm{SH}$ reactivity. The addition of the $\mathrm{SH}$ reagent iodoacetamide inhibits sperm respiration and motility and reduces $\mathrm{pH}$. HNE also inhibits respiration in bovine spermatozoa (I. G. White \& M. L. Selley, unpublished observations). Since HNE is highly active towards SH groups (Esterbauer et al., 1975, 1976), it seems reasonable to suppose that SH 
groups may be a target in the spermicidal action of HNE. The effect of seminal plasma in protecting spermatozoa from the toxic effects of HNE may be related to the presence of protein $\mathrm{SH}$ groups. A similar protection by seminal plasma against the spermicidal effect of exogenous peroxidized fatty acids on washed human spermatozoa has been reported (Jones et al., 1979).

Seminal plasma suppresses human lymphocyte responses to mitogens and alloantigens (Stites \& Erickson, 1975). HNE has a similar effect, a concentration of only $1 \mu \mathrm{M}$ suppressing the proliferative response (Tessitore et al., 1987). The generation of HNE by human spermatozoa may be responsible for the lack of an immune response by females against seminal antigens. Human semen contains histocompatibility antigens and is a good stimulator of lymphocyte transformation (Levis $e t$ al., 1976). The suppression of local immune responses in the female reproductive tract may protect sperm from elimination or the development of hypersensitivity in the female.

The presence of HNE in human semen may be of particular importance in the pathogenesis of the acquired immune deficiency syndrome (AIDS). There is evidence that impaired cellular immunity occurs in male homosexuals seronegative for HIV and that this is associated with receptive anal intercourse (Ratnam et al., 1986). Increased concentrations of HNE in semen may render it more immunosuppressive and increase susceptibility to HIV infection in semen recipients.

It has been suggested that semen may play a role in the etiology of cervical cancer (Kessler, 1974) and there is evidence that semen may be a cause of anal cancer (Daling et al., 1987). HNE could be partly responsible, since subcytotoxic concentrations of HNE which do not change the mitotic index increase the number of mononuclei and cause increased frequency of sister chromatid exchange and chromosomal aberrations in cultured rat hepatocytes (Griffin \& Segall, 1986). HNE forms cyclic adducts with deoxyguanosine (Winter et al., 1986) and inhibits the DNA repair mechanism (Krokan et al., 1985).

We thank Professor Hermann Esterbauer of the Institute of Biochemistry, University of Graz, for his generous gift of HNE and Pam McAllister of Macquarie Pathology Services Pty Ltd for collecting the semen samples.

\section{References}

Aitken, R.J. \& Clarkson, J.S. (1987) Cellular basis of defective sperm function and its association with the genesis of reactive oxygen species by human spermatozoa. J. Reprod. Fert. 81, 459.469.

Barrera, G., Martinotti, S., Fazio, V., Manzari, V., Paradisi, L., Parola, M., Frati, L. \& Dianzani, M.U. (1987) Effect of 4-hydroxynonenal on c-myc expression. Toxicol. Pathol. 15, 238-240.

Benedetti, A., Comporti, M. \& Esterbauer, H. (1980) Identification of 4-hydroxynonenal as a cytotoxic product originating from the peroxidation of liver microsomal lipids. Biochim. biophys. Acta 620, 281-296.

Buffinton, G.D., Hunt, N.H., Cowden, W.B. \& Clark, I.A. (1988) Detection of short-chain carbonyl products of lipid peroxidation from malaria parasite (Plasmodium vinckei) - infected red blood cells exposed to oxidative stress. Biochem. J. 249, 63-68.

Clark, l.A., Butcher, G.A., Buffinton, G.D., Hunt, N.H. \& Cowden, W.B. (1987) Toxicity of certain products of lipid peroxidation in the human malaria parasite Plasmodium falciparum. Biochem. Pharm. 36, 543- 546.

Curzio, M., Esterbauer, H., Di Mauro, C., Cecchini, G. \& Dianzani, M.U. (1986) Chemotactic activity of the lipid peroxidation product 4-hydroxynonenal and homologous hydroxyalkenals. Biol. Chem. HoppeSeyler 367, 321 - 329.

Daling, J.R., Weiss, N.S., Hislop, G.H., Madden, C., Coates, R.J., Sherman, K.J., Ashley, R.L., Beagrie, M., Ryan, J.A. \& Corey, L. (1987) Sexual practices, sexually transmitted diseases, and the incidence of anal cancer. New Engl. J. Med. 317, 973-977.

Esterbauer, H., Benedetti, A., Lang, J., Fulceri, R., Fauler, G., Comporti, M. (1986) Studies on the mechanism of formation of 4-hydroxynonenal during microsomal lipid peroxidation. Biochim. biophys. Acta 876, $154-166$.

Esterbauer, H., Ertl, A.\& Scholz, N. (1976) The reaction of cysteine with $\alpha, \beta$-unsaturated aldehydes. Tetrahedron 32, 285-289.

Esterbauer, H., Cheeseman, K.H., Dianzani, M.U., Poli, G., Slater, T.F. (1982) Separation and characterization of the aldehydic products of lipid peroxidation stimulated by ADP-Fe ${ }^{2+}$ in rat liver microsomes. Biochem. J. 208, 129-140.

Esterbauer, H. \& Weger, W. (1967) Über die Wirkungen von Aldehyden auf gesunde und maligne. Zellen, 3. Mitt: Synthese von homologen 4-hydroxy-2alkenalen, II. Mh. Chem. 98, 1994-2000. 
Esterbauer, H., Zollner, H. \& Scholz, N. (1975) Reaction of glutathione with $\alpha, \beta$-conjugated carbonyls. $Z$. Naturf. 30c, 466-473.

Griffin, D.S. \& Segall, H.J. (1986) Genotoxicity and cytotoxicity of selected pyrrolizidine alkaloids, a possible alkenal metabolite of the alkaloids, and related alkenals. Toxicol. appl. Pharmac. 86, 227--234.

Hauptlorenz, S., Esterbauer, H., Moll, W., Pumpel, R., Schauenstein, E. \& Puschendorf, B. (1985) Effects of the lipid peroxidation product 4-hydroxynonenal and related aldehydes on proliferation and viability of cultured Ehrlich ascites tumor cells. Biochem. Pharmac. 34, 3803-3809.

Hino, H., Schackmann, R.W. \& Shapiro B.M. (1986) Protein sulfhydryl reactivity and sperm activation. Prog. clin. Biol. Res. 217B, 69-73.

Hoff, H.F., O'Neill, J., Chisolm, G.M., Cole, T.B., Quehenberger, O., Esterbauer, H. \& Jürgens, G. (1989) Modification of low density lipoprotein with 4-hydroxynonenal induces uptake by macrophages. Arteriosclerosis 9, 538-549.

Jones, R., Mann, T. \& Sherins, R. (1979) Peroxidative breakdown of phospholipids in human spermatozoa, spermicidal properties of fatty acid peroxides and protective action of seminal plasma. Fert. Steril. 31, $53 \mathrm{l}-537$.

Kaneko, T., Kaji, K. \& Matsuo, M. (1988) Cytotoxicities of a linoleic acid hydroperoxide and its related aliphatic aldehydes toward cultured human umbilical vein endothelial cells. Chem.-Biol. Interact. 67, 295-304.

Kessler, I.I. (1974) Perspectives on the epidemiology of cervical cancer with special reference to the herpes virus hypothesis. Cancer Res. 34, 1091-1110.

Krokan, H., Grafstrom, R.C., Sundqvist, K., Esterbauer, H. \& Harris, C.C. (1985) Cytotoxicity, thiol depletion and inhibition of $O$-6-methylguanine-DNA methyltransferase by various aldehydes in cultured human bronchial fibroblasts. Carcinogenesis 6, 1755-1759.

Levis, W.R., Whalen, J.J. \& Sherins, R.J. (1976) Mixed cultures of sperm and leukocytes as a measure of histocompatibility in man. Science, N. Y. 191, 302-304.

Niehaus, W.G., Samuelsson, B. (1968) Formation of malonaldehyde from phospholipid arachidonate during microsomal lipid peroxidation. Eur. $J$. Biochem. 6, 126130.

Paradisi, L., Panagini, C., Parola, M., Barrera, G. \& Dianzani, M.U. (1985) Effects of 4-hydroxynonenal on adenylate cyclase and $5^{\prime}$-nucleotidase activities in rat liver plasma membranes. Chem.-Biol. Interact. 53, 209-217.

Poli, E., Dianzani, M.U., Cheeseman, K.H., Slater, T.F., Lang, J. \& Esterbauer, H. (1985) Separation and characterization of the aldehydic products of lipid peroxidation stimulated by carbon tetrachloride or ADP-iron in isolated rat hepatocytes and rat liver microsomal suspensions. Biochem. J. 227, $629-638$.
Ratnam, K.V., Wong, T.W., Lee, J., Kamarrudin, A., Sng, E.H. \& Ong, Y.U. (1986) Effect of ano-receptive homosexual practice on $\mathrm{T}$ lymphocytes and delayed hypersensitivity in transexuals. Aust. N.Z.J. Med.16, $757 \cdot 760$.

Selley, M.L., McGuiness, J.A., Jenkin, L.A., Bartlett, M.R. \& Ardlie, N.G. (1988) Effect of 4-hydroxy-2,3trans-nonenal on platelet function. Thromb. Haemost. 59, 143-146.

Selley, M.L., Bartlett, M.R., McGuiness, J.A., Hapel, A.J., Ardlie, N.G. \& Lacey, M.J. (1989) Determination of the lipid peroxidation product trans-4-hydroxy-2nonenal in biological samples by high-performance liquid chromatography and combined capillary column gas chromatography-negative-ion chemical ionisation mass spectrometry. J. Chromat. (Biomed. Appl.) 488, 329-340.

Slakotos, A.N., Bray, R., Dratz, E., van Kuijk, F., Sevanian, A. \& Koppang, N. (1988) 4-Hydroxynonenal: a specific indicator for canine neuronal-retinal ceroidosis. Am. J. Med., Genet. Supp. 5, 17[-181.

Slater, T.F. (1984) Free-radical mechanisms in tissue injury. Biochem. J. 222, 1-15.

Stites, D.P. \& Erickson, R.P. (1975) Suppressive effect of seminal plasma on lymphocyte activation. Nature, Lond. 253, 727-729.

Tessitore, L., Matera, L., Bonelli, G., Baccino, F.M. \& Dianzani, M.U. (1987) Aliphatic aldehydes inhibit the proliferative response of human peripheral blood lymphocytes to phytohemagglutinin and alloantigens. Chem.-Biol. Interact. 62, 217-226.

Trounson, A. (1983) Factors controlling normal embryo development and implantation of human oocytes fertilized in vitro. In Fertilization of the Human Egg in vitro, pp. 235-250. Eds H. M. Beier \& H. R. Lindner. Springer-Verlag, Berlin.

van Kuijk, F.J.G.M., Thomas, D.W., Stephens, R.J. \& Dratz, E.A. (1986) Occurrence of 4-hydroxyalkenals in rat tissues determined as pentafluorobenzyl oxime derivatives by gas chromatography-mass spectrometry. Biochem. biophys. Res. Commun. 139, 144-149.

Winter, C.K., Segall, H.J. \& Haddon, W.F. (1986) Formation of cyclic adducts of deoxyguanosine with the aldehydes trans-4-hydroxy-2-hexenal and trans4-hydroxy-2-nonenal in vitro. Cancer Res. 46, $5682-5686$.

Witz, G., Lawrie, N.J., Amoruso, M.A. \& Goldstein, B.D. (1985) Inhibition by reactive aldehydes of superoxide anion radical production in stimulated human neutrophils. Chem.-Biol. Interact. 53, 13-23.

Yoshino, K., Sano, M., Fujita, M. \& Tomita, I. (1986) Formation of aliphatic aldehydes in rat plasma and liver due to vitamin $\mathrm{E}$ deficiency. Chem. pharm. Bull. 34, 5184-5187.

Received 4 April 1990 